\title{
We Are the First to Applaud You Regarding Your Efforts in COVID-19: A Message from the African Diaspora to Our Brothers and Sisters of Africa
}

\author{
Cato T. Laurencin ${ }^{1,2} \cdot$ Aneesah McClinton ${ }^{1}$ \\ Received: 29 April 2020 / Revised: 29 April 2020 / Accepted: 11 May 2020 / Published online: 4 June 2020 \\ (C) W. Montague Cobb-NMA Health Institute 2020
}

\begin{abstract}
As African countries address the COVID-19 pandemic, we applaud the continent and its efforts in the crisis, and offer a message that includes lessons learned from the American experience.
\end{abstract}

Keywords COVID-19 $\cdot$ Coronavirus $\cdot$ Pandemic $\cdot$ Africa $\cdot$ Action $\cdot$ Black $\cdot$ Health $\cdot$ Disparities $\cdot$ Diaspora $\cdot$ Racism

As of this day, the United States of America has, within its geographic bounds, the most documented cases and deaths from coronavirus disease 2019 (COVID-19) in the world. The global devastation of the crisis continues to evolve as the virus reaches regions of the world at various time points with the potential to impart sickness, death, and economic instability. For America, it has exposed the societal inequities that racial injustice has caused, as Black Americans are disproportionately affected by the virus. The World Health Organization (WHO) has warned that Africa could become the next epicenter of the global pandemic [1]. However, the pandemic is currently taking a different course on the continent [2], and we are optimistic that this crisis will continue to be addressed head on. We applaud you for your efforts, and present a perspective on our experiences in the US.

\section{You are Taking Decisive Action Early}

The first lesson from America is that early recognition and swift, decisive action must be taken, and taken early. In the

Cato T. Laurencin

laurencin@uchc.edu

1 Connecticut Convergence Institute for Translation in Regenerative Engineering, UConn Health, Farmington, CT 06030, USA

2 The Africana Studies Institute, University of Connecticut, Storrs, CT 06269, USA
US experience of the pandemic, there were few known early cases on US soil. The social gatherings continued, and hot spots emerged, including a cluster of cases in New Rochelle, NY [3]. Mardi Gras festivities likely contributed to the accelerated spread in New Orleans [4]. As a country, we did not take decisive action at the earliest possible point. Other countries must get to where we are now in acknowledging the level of threat and the level of extreme measures that must be taken to combat the virus successfully. However, they must get to this endpoint much faster than we did in America. The precise moment when the US recognized the severe acute respiratory syndrome coronavirus 2 (SARS-CoV-2) as an immediate threat necessitating prompt action is controversial. It is unclear when the insufficient number of personal protective equipment, ventilators, and inadequate testing capacity was first identified. A less contested view is that valuable time was lost in the interim. Social distancing was advised weeks into the crisis, with enforcement discretion left up to individual states. Later, the Centers for Disease Control and Prevention (CDC) began to recommend face coverings in public, and the Defense Production Act was invoked for desperately needed ventilators and medical supplies. It must be emphasized that other countries must get to where we are now in acknowledging the threat and the extreme measures that must be taken to combat the virus, but get their faster than we did in America. Personal protective equipment, face coverings in public, and amassing testing supplies and ventilators must be a high priority.

African countries are drawing on their experiences with pandemic outbreaks, including Ebola and influenza, to tackle 
COVID-19 [5]. Africa's previous experiences will make the difference, in which teams of health care experts already trained in the management of infectious disease are available, and previously established sentinel surveillance systems can be utilized. African countries are responding to this crisis in a manner that understands its resources, a reflection of knowing your strengths and current realities in order to adapt. The efforts taken by many African countries have not gone unnoticed and include establishing systems for contact tracing. Senegal employed early planning strategies at the outset of the pandemic and is in the process of developing an affordable testing kit. Ghana has implemented "pool testing," a strategy that combines samples for testing and subsequently tests individual samples only if there is a positive test for the group, effectively increasing testing capacity for the virus [6]. According to the foreign minister of Equatorial Guinea, contact tracing has been established and individuals are placed in hotels if needed (personal communication, April, 2020). Various countries, including Uganda and Nigeria, have organized presidential COVID19 task forces [7].

\section{You are a United Front}

Early images and stories emerged of a shared mission and collective solidarity at the outset of the pandemic in the US. This has been clouded as a nation becomes divided. Protesters have taken to the streets to demand the reopening of states, and states are bidding against each other to secure desperately needed supplies [8].

To be successful in fighting COVID-19, there must be unity of purpose. Martin Luther King, Jr. once said, "We may have all come on different ships, but we're in the same boat now." There is no place in a deadly infection crisis for competition, assigning blame, or political disputes.

As stated earlier, from the American experience, the pandemic has been particularly hard on Black populations, members of the African diaspora. Early data has revealed a disproportionate impact on Black communities, and we are one of the first to highlight this disproportionate impact in the peerreviewed literature [9]. The disparity is, in part, attributed to a medical system plagued by unconscious bias [10] that stems from a legacy of racism in America. Other infectious diseases, including human immunodeficiency virus (HIV), have become a scourge for Black Americans in the US [11, 12]. A recent report published by the CDC found that while Black Americans comprised $33 \%$ of the hospitalizations in the COVID-19-Associated Hospitalization Surveillance Network (COVID-NET), they only made up $18 \%$ of the analyzed population, revealing a disproportionate impact of the virus on Black communities [13]. In New York City, one of the hardest hit regions in the nation, the death rate for Black Americans is 92.3 deaths per 100,000, the highest amongst any group including Hispanic/Latinx (74.3), White (45.2), and Asian (34.5) [14]. We must be extremely assertive on the continent in combating the virus to avoid similar catastrophic consequences. Nothing short of a united effort will be successful. The African Union has a unified voice and is making great strides.

\section{You are Leading by Your Example}

Inadequate testing in the US [15] is one of the primary reasons this crisis has continued to have a detrimental impact. Testing should be accompanied by community tracer teams that seek out first-degree contacts to further test. Strict quarantines must be observed for all positive cases. An important lesson can be learned from a study [16] conducted in Shenzhen, China in which the clinical outcomes of 55 asymptomatic carriers of SARS-CoV-2 were analyzed. The patients were identified via the systematic screening of family members of individuals diagnosed with COVID-19. All asymptomatic individuals underwent immediate isolation and early treatment. During their hospitalization, all patients progressed to either mild, moderate, or severe symptoms. All survived and were eventually discharged home. None required admission for ventilator support. The early treatment strategy is ideal, and where space is limited, pop-up mini-hospitals can be established in tents to provide supportive care and effectively isolate those diagnosed with COVID-19. Nigeria is already employing isolation centers [7]. In addition, home to hospital conversions may prove beneficial. Early treatment and support may aid in easing the medical burden by decreasing the extensive hospitalizations and ventilator support required in the US. If testing is not available, strict clinical criteria should be used and individuals quarantined. Symptoms should be treated proactively.

We anticipate that you will continue to lead by your example. Madagascar's announcement of an herbal remedy for COVID-19 has garnered much attention [6], and while more testing is necessary to establish its efficacy, it exemplifies that Africa is looking to itself for solutions and embracing its own to find them.

\section{Conclusion}

Amidst the many projections of human suffering and death, a real tragedy would occur if we do not learn from and prepare for subsequent medical surprises and disasters [17]. As for what lies ahead, many of us are unsure, although it is apparent that we are embarking on incredibly trying times. We applaud your efforts thus far, for we of African descent are not strangers to adversity, and the current times call on us to draw from our endless reserve of unwavering resilience. 
Acknowledgements Dr. Laurencin is the recipient of the UNESCO Equatorial Guinea International Prize for Research in the Life Science presented at the meeting of the African Union in February 2020. He is an Associate Fellow of the African Academy of Sciences.

Funding Information Dr. Cato T. Laurencin received support from the NIH BUILD Award U54MD009476.

\section{Compliance with Ethical Standards}

Conflict of Interest The authors declare that they have no conflict of interest.

Ethical Approval This article does not contain any studies with human participants or animals performed by any of the authors.

Informed Consent Not applicable

\section{References}

1. Coronavirus: Africa could be next epicentre, WHO warns [Internet]. BBC. 2020 [cited 2020 Apr 20]. Available from: https://www.bbc.com/news/world-africa-52323375.

2. Covid-19 'taking a different path in Africa', says WHO [Internet]. The Guardian. 2020 [cited 2020 May 23]. Available from: https:// www.theguardian.com/world/2020/may/23/coronavirus-latest-ata-glance.

3. Morales M, Andone D. What life is like inside the coronavirus containment zone in New Rochelle, New York [Internet]. CNN. 2020 [cited 2020 Apr 20]. Available from: https://www.cnn.com/2020/03/ 12/us/new-rochelle-coronavirus-containment-area/index.html.

4. Fausset R, Kravitz D. Why New Orleans pushed ahead with Mardi Gras, even as it planned for coronavirus [Internet]. The New York Times. 2020 [cited 2020 Apr 20]. Available from: https://www. nytimes.com/2020/04/13/us/coronavirus-new-orleans-mardi-gras. html.

5. Drawing on Ebola readiness to tackle COVID-19 [Internet]. WHO Africa. 2020 [cited 2020 Apr 20]. Available from: http://whotogowhoafroccmaster.newsweaver.com/JournalEnglishNewsletter/ bfzau $1 \mathrm{~b} 6 \mathrm{ss} 5 \mathrm{y} 48$ iiujdam4 ?lang $=$ en $\& \mathrm{a}=2 \& \mathrm{p}=56814350 \& \mathrm{t}=$ 31103707.

6. Hirsch A. Why are Africa's coronavirus successes being overlooked? [Internet]. The Guardian. 2020 [cited 2020 May 23].
Available from: https://www.theguardian.com/commentisfree/ 2020/may/21/africa-coronavirus-successes-innovation-europe-us.

7. African Center for Strategic Studies. African adaptations to the COVID-19 response [Internet]. 2020 [cited 2020 May 23]. Available from: https://africacenter.org/spotlight/africanadaptations-to-the-covid-19-response/.

8. Feiner L. States are bidding against each other and the federal government for important medical supplies - and it's driving up prices [Internet]. CNBC. 2020 [cited 2020 Apr 20]. Available from: https://www.cnbc.com/2020/04/09/why-states-and-the-federalgovernment-are-bidding-on-ppe.html

9. Laurencin CT, McClinton A. The COVID-19 pandemic: a call to action to identify and address racial and ethnic disparities. J Racial Ethn Health Disparities. 2020;7:398-402.

10. Milam AJ, Furr-Holden D, Edwards-Johnson J, Webb B, Patton JW, Ezekwemba NC, et al. Are clinicians contributing to excess African American COVID-19 deaths? Unbeknownst to them, they may be. Heal Equity. 2020;4.1:139-41.

11. Laurencin CT, Christensen DM, Taylor ED. HIV/AIDS and the African-American Community: A State of Emergency. J Natl Med Assoc. 2008;100(1):35-43.

12. Laurencin CT, Murdock CJ, Laurencin L, Christensen DM. HIV/ AIDS and the African-American Community 2018: a Decade Call to Action. J Racial Ethn Health Disparities. 2018;5:449-58.

13. Garg S, Kim L, Whitaker M, Al E. Hospitalization rates and characteristics of patients hospitalized with laboratory-confirmed coronavirus disease 2019 - COVID-NET, 14 States, March 1-30, 2020. MMWR Morb Mortal Wkly Rep. 2020;69:458-64.

14. COVID-19 in Racial and Ethnic Minority Groups [Internet]. Centers for disease control and prevention. 2020 [cited 2020 May 23]. Available from: https://www.cdc.gov/coronavirus/2019ncov/need-extra-precautions/racial-ethnic-minorities.html.

15. Maxmen A. Thousands of coronavirus tests are going unused in US labs. Nature. 2020;580:312-3.

16. Wang Y, Liu Y, Liu L, Wang X, Luo N, Li L. Clinical Outcomes in 55 Patients With Severe Acute Respiratory Syndrome Coronavirus 2 Who Were Asymptomatic at Hospital Admission in Shenzhen, China. J Infect Dis. 2020;221(11):1770-4.

17. Laurencin CT, McClinton A. Medical surprise anticipation and recognition capability: a new concept for better health care. J Racial Ethn Health Disparities. 2019;6:869-73.

Publisher's Note Springer Nature remains neutral with regard to jurisdictional claims in published maps and institutional affiliations. 